\title{
Alleviation of Salinity Effects by Poultry Manure and Gibberellin Application on growth and Peroxidase activity in pepper
}

\author{
Duraid Kamil Abass AlTaey \\ AlQasim Green Uni., Agriculture College, Horticultur dept. , Ph.D. in plant physiology \\ 009647831010388; duraidalatey@ gmail.com
}

\begin{abstract}
Capsicum is one of the most widely consumed vegetables and is also used as a spice for its pungency. Many species of Capsicum are being cultivated worldwide. Capsicum is considered as a commercial crop for their economic value. However, the yield of the crop suffers severely due to salt stress, Soil salinity reduces water availability of plant roots via negative (low) osmosis potential, as well as decrease of germination dynamics of plant seeds by ionic toxicity of $\mathrm{Na}$ and $\mathrm{Cl}$, Significant differences in fruit-set, yield, photo synthetic rates, stomata conductance, total chlorophyll content, proline, In general, salinity affects almost every aspect of the physiology and biochemistry of plants.

The aim of this study was to determine the salt tolerance of pepper (Capsicum annuum L) under salinity stress by saline irrigation water, Poultry and gibberellins applications were used to alleviated the negative effects on growth parameters and yield of Pepper under salinity stress.
\end{abstract}

The water salinity levels led to a significant elevation in the values of electrical conductivity of the soil with the peroxidase activity, and Sodium and proline contents in leaves, while resulting in decrease in growth parameters and leave contents of (NPK), The poultry and gibberellins applications increased the growth parameters ( Dry weight of shoot and root \&fruit weight) and (NPK) contents in leaves with slight dropping of peroxidase activity in leaves while a clear dropping of sodium and proline contents in leave.

That possible to mitigation the negative affect of salt stress by some application like exogenous hormones and Decomposed organic matter to solve the disruption of endohormons and lack of available nutrients under salt stress, and elevation of osmotic stress in soil solution in roots area.

The GA \& poultry application improved the growth and it has increased the Pepper tolerance to the abiotic stress which was exerted by saline irrigation water.

Keywords - salinity, salt stress, pepper, Gibberellins, organic matter, poultry manure, nutrient availability.

\section{INTRODUCTION}

Growth and productivity of the plants are affected due to many abiotic stresses like salinity, heat, cold and drought etc.(Sana et al., 2016) Which are leading towards hundreds of billions of crop losses each year (Atkinson, N.J. and P.E. Urwin. 2012). Soil salinity is the most devastating among them (Shahbaz, M. and M. Ashraf. 2013) which not only limits plant growth and metabolism but also poses a foremost intimidation to sustainable agricultural production throughout the world particularly in arid and semi- arid areas (Tayyab et al.,2016), More than 400 million hectares of the total geographical area of the world are affected by high concentration of the soluble salts (Sana et al., 2016) Secondary salinization from irrigation water is a growing worldwide problem as more than $6 \%$ of agricultural land has become saline (Al-Taey,2009), Salt stress severely inhibits plant growth for two reasons: first by an osmotic or water- deficit effect of salinity and second by a salt-specific or ion-excess effect of $\mathrm{NaCl}$. Moreover, plants subject to salinity stress conditions produce cytotoxic activated oxygen that can seriously disrupt normal metabolism, through oxidative damage of lipids, proteins, and nucleic acids (Abbaspour,2012), Salinization can also lead to excess intracellular production of reactive oxygen species (ROS) such as the superoxide radical (O2 --), the hydroxyl radical $(\mathrm{OH} \cdot)$, hydrogen peroxide $(\mathrm{H} 2 \mathrm{O} 2)$ and singlet oxygen (1O2) 6- (AL-Taey and Saadoon,2012), which hinders growth because of its toxic and osmotic effects, respectively, causing accumulation of ions in the protoplasm and physiological drought(Deuner et al.,2011), to defend against such oxidants, plants have evolved specific protective mechanisms, involving antioxidant molecules and enzymes that protect against the potentially-cytotoxic species of activated oxygen. Adaptation to salt stress requires alterations ingene.

Pepper (Capsicum annuиmL.) is the second most widely consumed vegetable in the world and an excellent source of many essential nutrients for humans, especially vitamin C, phenolic compounds, 
flavonoids, to copherols (vita-min E), carotenoids (pro vitamin A), capsaicinoids, and calcium. Additionally, some pepper cultivars contain significant quantities of capsaicinoids, a group of pungent phenolic derived compounds with strong physiological and pharmacological properties. Thus, the growing global demand of pepper fruits implies several strategies to increase crop production and fruit quality or promote the investigation to improve the plant resistance to environmental stresses (Jimenez-Garcia et al.,2014), Pepper is a moderately sensitive to salt stress (Lee,2006) and it is grown under protected glasshouse conditions in temperate regions and in the open field under warm Mediterranean climates, it is frequently exposed to saline conditions brought about by saline irrigation water containing amounts of salts including sodium chloride(Kijne,2003)

Salinization promotes an imbalance in the absorption of essential nutrients, causing metabolic disorders, which inhibit growth (Maia, et al, 2012)there are an extensive number of plant nutrition studies from all over the world, but the studies were mostly conducted to determine best management practices under non-saline conditions. Some studies have been conducted to determine if certain nutrients have alleviative effects on salinity tolerance (El-Sidding and Ludders, 1994). Some studies indicated a positive effect of fertility on salt tolerance while some reported that there was no alleviative effect on salt tolerance, some Studies showed that application of fertilizers in saline soils might result in increased, decreased or unchanged plant salt tolerance. In other words, plant response to fertilizers depends on severity of salt stress in the root zone(Faiza and Amin,2009) However, in another similar study to (Gomez, et al,1996), found a positive yield response for pepper at all three salinity levels by increasing nutrient $\mathrm{N}$ from 2 to $15 \mathrm{mM}$ in a solution culture. However the effect of $\mathrm{N}$ on relative yield was not clear. The first salinity level above the control $(25 \mathrm{mMNaCl})$ had a lower relative yield at lower $\mathrm{N}$ and with subsequent increases in salinity it had a higher relative yield. phytohormons are considered the most important endogenous substances for modulating physiological and molecular responses, a critical requirement for plant survival as sessile organisms, Phytohormons act either at their site of synthesis or elsewhere in plants following their transport(Shabir,et al,2016).

The gibberellins (GAs) are a large group of tetracyclic diterpenoid carboxylic acids, The GAs show positive effects on seed germination, leaf expansion, stem elongation, flower and trichome initiation, and flower and fruit development, They are essential for plants throughout their life cycle for growth-stimulatory functions. They also promote developmental phase transitions. Interestingly, there is increasing evidence for their vital roles in abiotic stress response and adaptation (Colebrook, et al., 2014).Recently, experiments have been performed to investigate the role of GAs in osmotic stress response in Arabidopsis thaliana seedlings (Skirycz, et al, 2012; Maggio, et al, 2010)reported that GA3 treatment in tomato reduced stomata resistance and enhanced plant water use at low salinity. Likewise, GA3-priming increases grain yield due to the GA3-priming-induced modulation of ion uptake and partitioning (within the shoots and roots) as well as hormone homeostasis under saline conditions.

GAs are known to interact with all other phytohormons in numerous developmental and stimulus-response processes, the interactions between GA and ET include both negative and positive mutual regulation depending on the tissue and signaling case (Munteanu, et al., 2014)

Objectives:

The aim of this study was to determine the salt tolerance of pepper (Capsicum annuum L) under salinity stress by saline irrigation water, Poultry and gibberellins applications were used to alleviated the negative effects on growth parameters and yield of Pepper under salinity stress.

\section{MARTIAL \& METHODS}

This experiment was conducted under glass house of horticulture department, collage of in AL- Qasim green university at Novemb1st 2015, the Sweet pepper (Capsicum annuum L.) of RIDA cultivar from Netherland was used. The seedlings were planted in plastic pots containing $10 \mathrm{~kg}$ of soil (six pots for each treatment).Each one supplied with $0.5 \mathrm{gm}$ of NPK and granular fungicide. Seedlings were irrigated with river water $(1.2 \mathrm{dS} . \mathrm{m}-1 / \mathrm{cm})$ for ten days twice a day before salinity treatment, followed by irrigation (half of seedlings) with salted water $(6 \mathrm{dS} . \mathrm{m}-1 / \mathrm{cm})$ every day until seedlings were reaching 80 days old.

Plants were sprayed twice with of GA $(0,250 \mathrm{mg} / \mathrm{L})$ the first spray was two weeks after germination, the second spray was 4 weeks after the first spray.

Experiment was conducted according to split-split plot design with threefactors, The main factor is the water quality (1.2 dS.m-1 represented river water (W1) \& 6 dS.m-1 represented saline water (W2), the second factor (sub- plot) is the poultry fertilization levels with $10 \%$ (O1) $\& 30 \%(\mathrm{O} 2)$, The third factor (sub-sub-plot) is gibberellin levels with $(0,250 \mathrm{mg} /$ liter $)$ The Gibberellin $0 \%$ (G1) \& the $250 \mathrm{mg} / \mathrm{liter}$ (G2.) ,the data were analyzed statistically with Genstat discovery software. Means were statistically compared by L.S.D testat $p<5 \%$ 
level.

The figure (1) below show the experiment planer, included 24 treatments

\begin{tabular}{|c|c|c|}
\hline W1 01 G1 & W2 O2 G2 & W1 01 G2 \\
\hline$W 102$ G1 & W2 O1 G2 & W1 O2 G1 \\
\hline$W 101$ G2 & W2 01 G1 & W1 O2 G2 \\
\hline W1 02 G2 & W2 02 G1 & W1 01 G1 \\
\hline
\end{tabular}

\begin{tabular}{|c|c|c|}
\hline W2 O2 G2 & W1 O1 G1 & W2 O2 G1 \\
\hline$W 201$ G2 & $W 102$ G1 & W2 O1 G2 \\
\hline$W 201$ G1 & $W 101$ G2 & W2 O1 G1 \\
\hline W2 O2 G1 & W1 O2 G2 & W2 O2 G2 \\
\hline
\end{tabular}

\section{Measurement of growth attributes}

Three plants were harvested randomly from four replicates at mature stage (90 days after sowing). Plant height, Root length, number of leaves, leaf area, number of fruits, fresh and dry biomass ( $\mathrm{g}$ ) were recorded in harvested plants $\mathrm{Na}, \mathrm{K}$ Samples of leaf, stem and root were taken at grand period of growth for the analysis of different Cations $(\mathrm{Na}+\mathrm{K}+)$. Samples were dried and $0.5 \mathrm{gm}$ of each dry sample was taken for ash weight. Then solution of ash was made in $50 \mathrm{ml}$ of de-ionized water, and then dilutions were made in deionized water for mineral analysis. Concentration of Cations in samples was measured using PFP 1 Flame Photometer according to (Wiessmann and Nehring, 1960), the nitrogen determination according to (Jackson, 1958) while the determination of phosphorus in leaves was measured according to (Page, et al, 1982)

\section{Determination of Peroxidase Activity}

This was determined by measuring the increase in absorbance at $510 \mathrm{~nm}$ resulting from the decomposition of hydrogen peroxide (Trinder,1966)the Lambda $25 \mathrm{UV} / \mathrm{V}$ is spectrometer (Perkin Elmer) was adjusted to $510 \mathrm{~nm}$. The blank was a mixture of $1.4 \mathrm{ml}$ of phosphate buffer and $1.4 \mathrm{ml}$ of $\mathrm{H} 2 \mathrm{O} 2$ in the cuvette. The assay mixture contained 1.4 $\mathrm{ml}$ of phosphate buffer, $1.4 \mathrm{ml}$ of $\mathrm{H} 2 \mathrm{O} 2$ and $0.2 \mathrm{ml}$ of the extract. The increase in absorbance at $510 \mathrm{~nm}$ was recorded for 4 minutes. Then, $\Delta \mathrm{A} 240 / \mathrm{min}$ was calculated from the initial (45 second) linear portion of thecurve.

\section{Determination of proline.}

Proline colorimetric determination preceded according to (Bates, et al., 1973; Marin, et al, 2010)based on proline's reaction with ninhydrin ratio of $1: 1: 1$ solution of proline, ninhydrin acid and glacial acetic acid was incubated at $100^{\circ} \mathrm{C}$ for 1 hour. Thereaction was arrested in an iced bath and the chromophorewas extracted with $1 \mathrm{ml}$ toluene and its absorbance at 520 $\mathrm{nm}$ was determined spectrophotometerically $.0 .1 \mathrm{gm}$ of shoot and root tissues was suspended with $1 \mathrm{ml}$ of $3 \%$ sulfosalicylic acid and after centrifugation (10min at12,000 rpm) was mixed in a 1:1:1 ratio with ninhydrin acid and glacial acetic acid. The reaction and determination of proline were carried out similarly tothat described above The concentration of proline in tissues were determined dependingon standard curve of pureproline.

\section{RESULTS}

\section{1- Dry weight of shoot and root, fruit weight \& chlorophyll content in leaves.}

The figures $(2,3,4 \& 5)$ show a significant effect of poultry manure at $30 \%$ concentration on dry weight of shoot and root, fruit weight and chlorophyll content in leaves with boost rat was ( $130 \%, 93 \%, 99 \%$ \& 13\%) , sequentially according to $10 \%$ of poultry manure concentration, In a similar manner to gibberellin application of $250 \mathrm{mg} /$ liter with boost rate was (31\% $, 42 \%, 84 \% \& 14 \%$ ), sequentially according to 0 $\mathrm{mg} /$ liter of gibberellin concentration, but there is significant drop to dry weight of shoot and root $\&$ fruit weight with raising of water salinity, the dropping rat was $(45 \%, 34 \%, 58 \% \& 7 \%) \mathrm{g}$, sequentially, the interaction treatment among ( poultry $30 \%$ +gibberellin $250 \mathrm{mg}+$ irrigation water $1.2 \mathrm{ds} / \mathrm{m}$ ) achieved the highest means in dry weight of shoot and root, fruit weight \& chlorophyll content in leaves while the lowest means at treatment (poultry10\%, gibberellin $0 \%$,irrigation water $6 \mathrm{ds} / \mathrm{m}$ ) , the application of poultry manure and gibberellin treatment alleviated the negative affect of saline water in dry weight of shoot and root, fruit weight \&chlorophyll content with $(3.76,2.11,21.9 \& 49.9)$, sequentially according to treatment which irrigated by saline water without poultry and gibberellin application which recorded ( $1.48,0.65,9.8 \& 44.9)$ sequentially. 


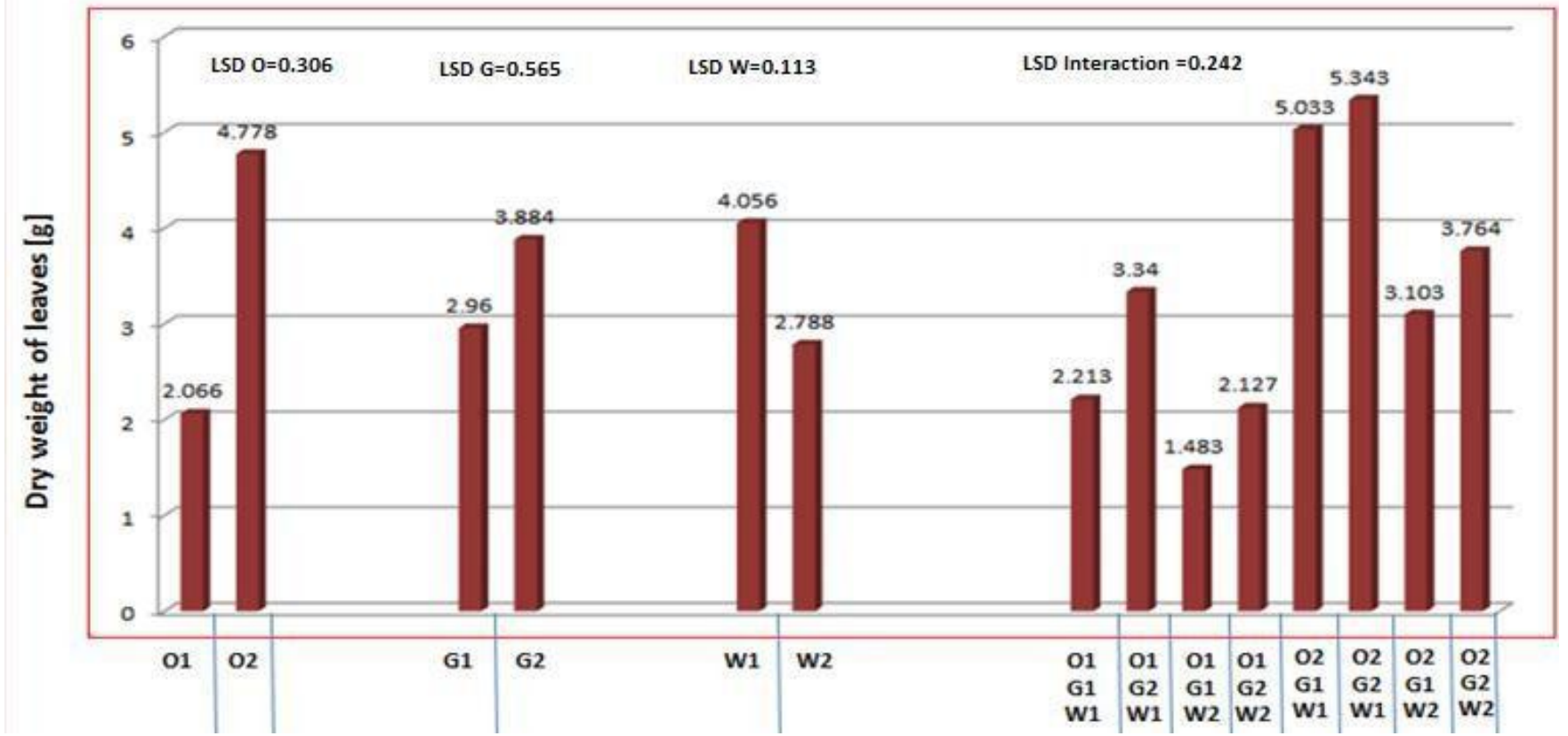

Fig.2: Shows the effect of water quality, poultry manure\& gibberellin with interaction betweenthem on the dry weightofleaves Water quality $(W)$ Poultry manure $(O)$ Gibberellin $(g)$

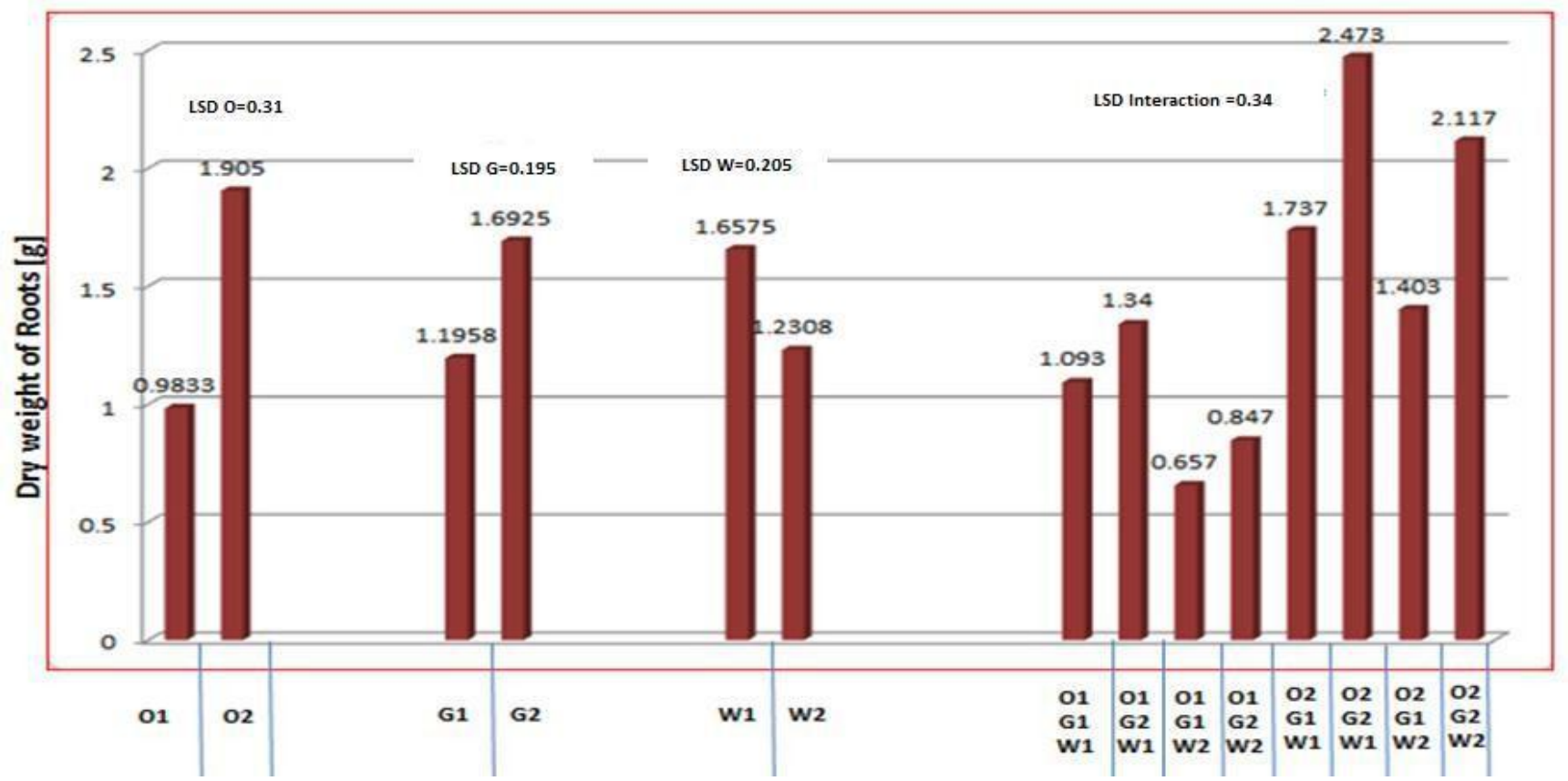

Fig.3: shows the effect of water quality, poultry manure \& gibberellin with interaction betweenthem on the dry weightof root Water quality $(W)$ Poultry manure $(O)$ Gibberellin $(g)$ 


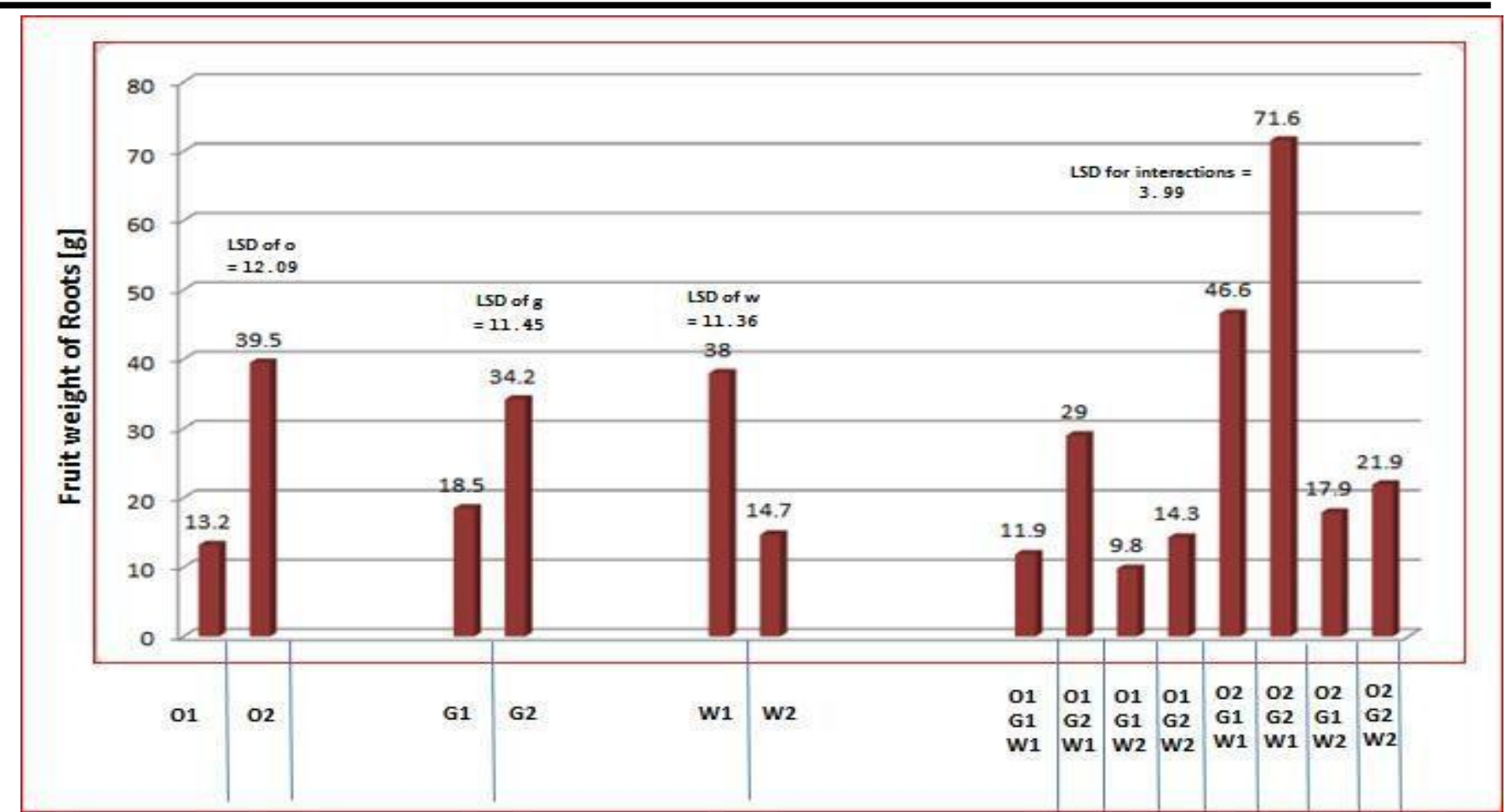

Fig.4: Shows the effect of water quality, poultry manure \& gibberellin with interaction betweenthem on the fruit weight Water quality (W) Poultry manure (O) Gibberellin( $g$ )

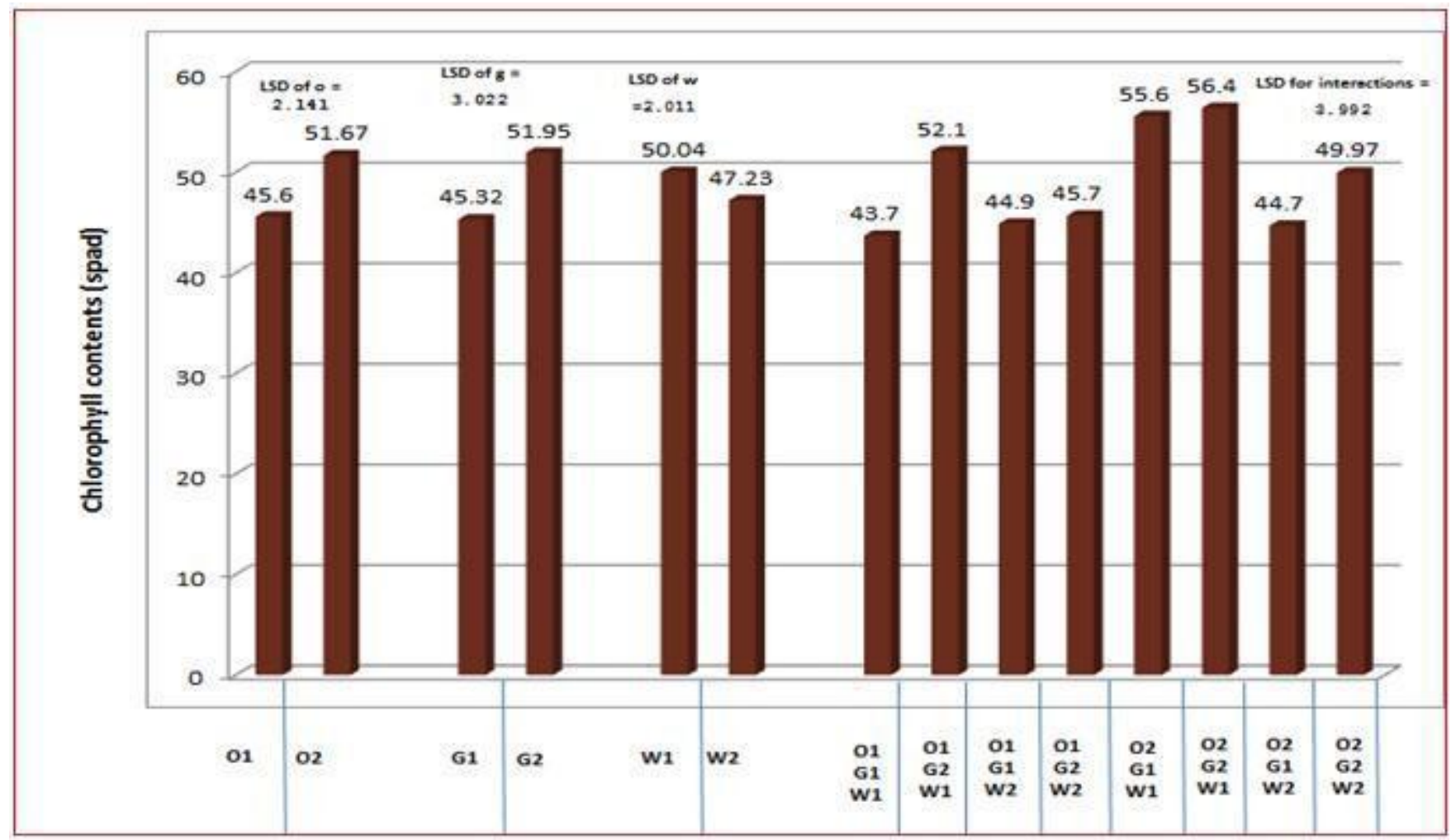

Fig.5: shows the effect of water quality, poultry manure\& gibberellin with interaction between them on the chlorophyll contentinspad. Water quality (W) Poultry manure (O) Gibberellin( $g$ ) 
2-The Nitrogen, Phosphor, Potassium and Sodium in the leaves

The figures $(6,7,8 \& 10)$ show a significant effect of poultry manure at $30 \%$ concentration on Nitrogen, Phosphorus, Potassium content and $\mathrm{K} / \mathrm{Na}$ ratio in the leaves with boost rate was $(\% 70,64 \%, 23 \%, \& 78 \%)$, sequentially compare with $10 \%$ of poultry manure c8ेncentration, while the poultry fertilization due to reduction of sodium uptake in root nearly (38\%) figure(9), in comparison with treatments with $10 \%$ poultry fertilization. The gibberellin application of 250 $\mathrm{mg} /$ liter with increasing percentage of Nitrogen, Phosphorus, Potassium and K/Na $(26 \%, 16 \%, 8 \%$ \& $14 \%$ ), sequentially according to $0 \%$ gibberellin figures
$(6,7,8$ \& 10), same the way the gibberellin application led to reduction the Sodium content in leaves approximately $6 \%$, figure(9).

The saline water led to reduction in nitrogen, phosphorus, potassium and $\mathrm{K} / \mathrm{Na}$ ratio in the leaves compare to river water, there was anincrease differences in Sodium content in leaves when saline water was applied (figure9).

The interaction of water quality, poultry litter and gibberellin (W1O2G2) affected in nitrogen, phosphorus, potassium, content and the $\mathrm{K} / \mathrm{Na}$ ratio compared with (W1O1G1), Treatment (W1O2G2) produced lowest Sodium content compared with treatment (W2O1G1) figure 9.

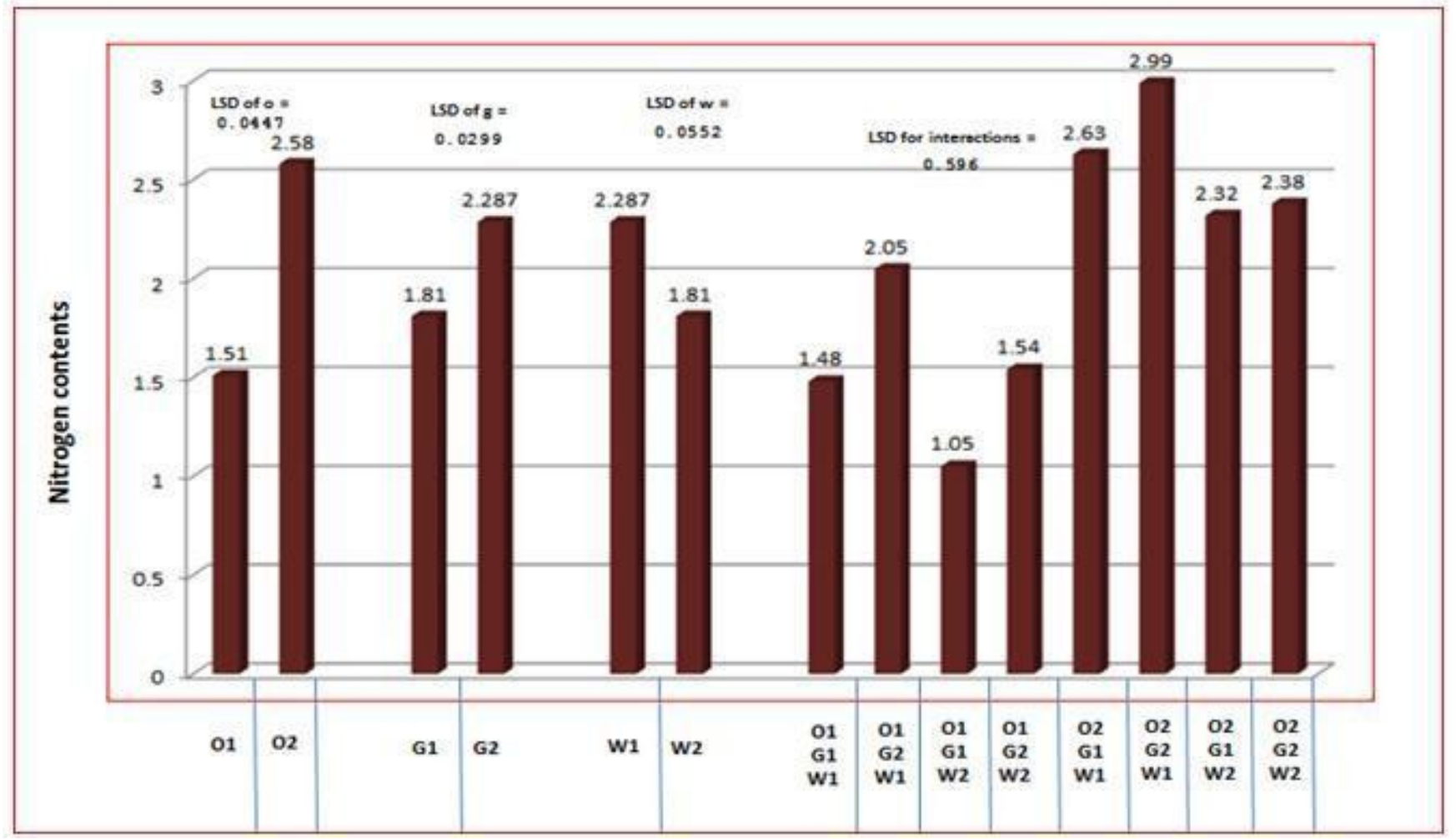

Fig.6: shows the effect of water quality, poultry manure \& gibberellin with interaction betweenthem on the $N$ contentinleaves. Water quality (W) Poultry manure (O) Gibberellin( $g$ ) 


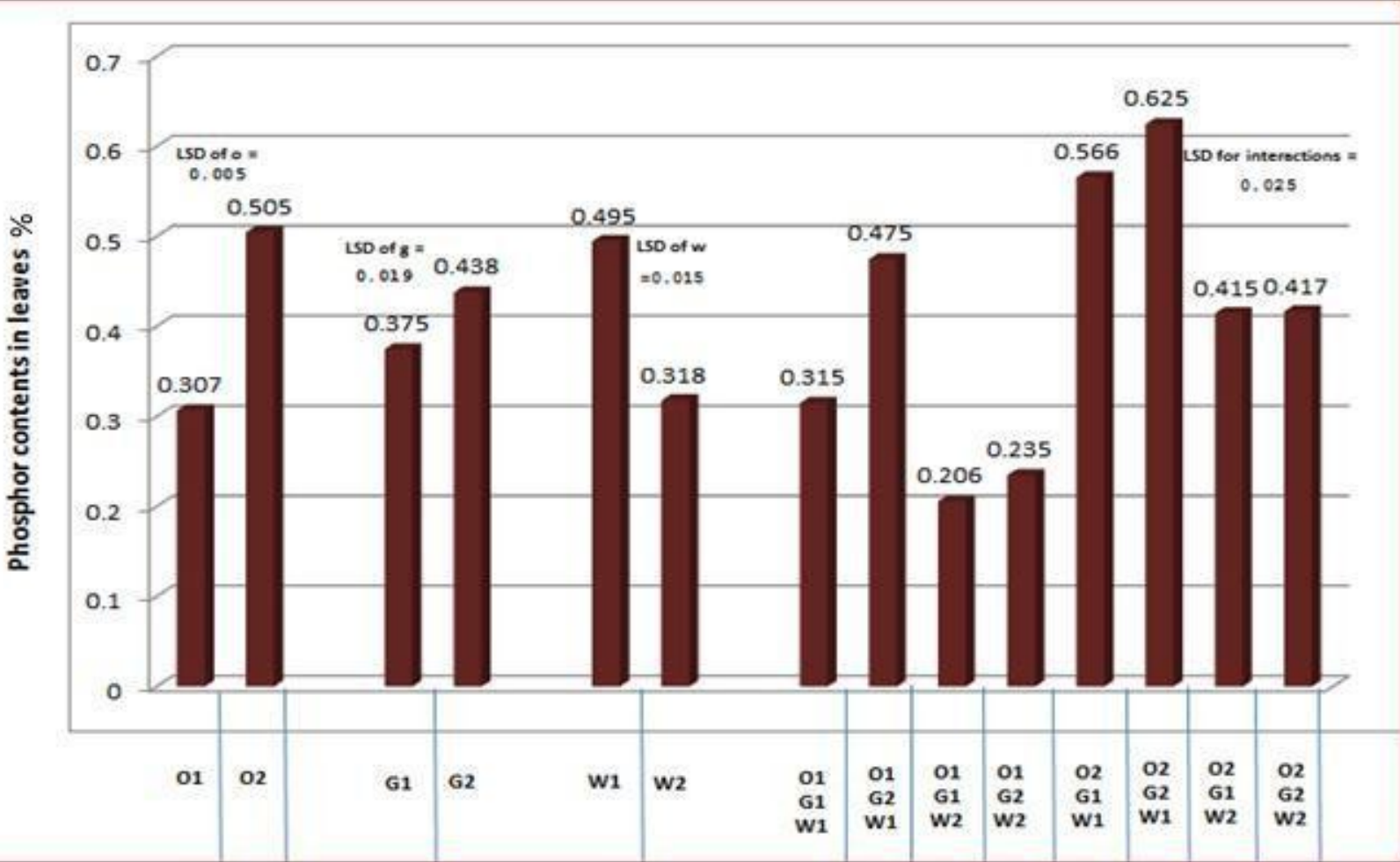

Fig.7: shows the effect of water quality, poultry manure\& gibberellin with interaction betweenthem on the

Phosphorus contentinleaves. Water quality (W) Poultry manure (O) Gibberellin(g)

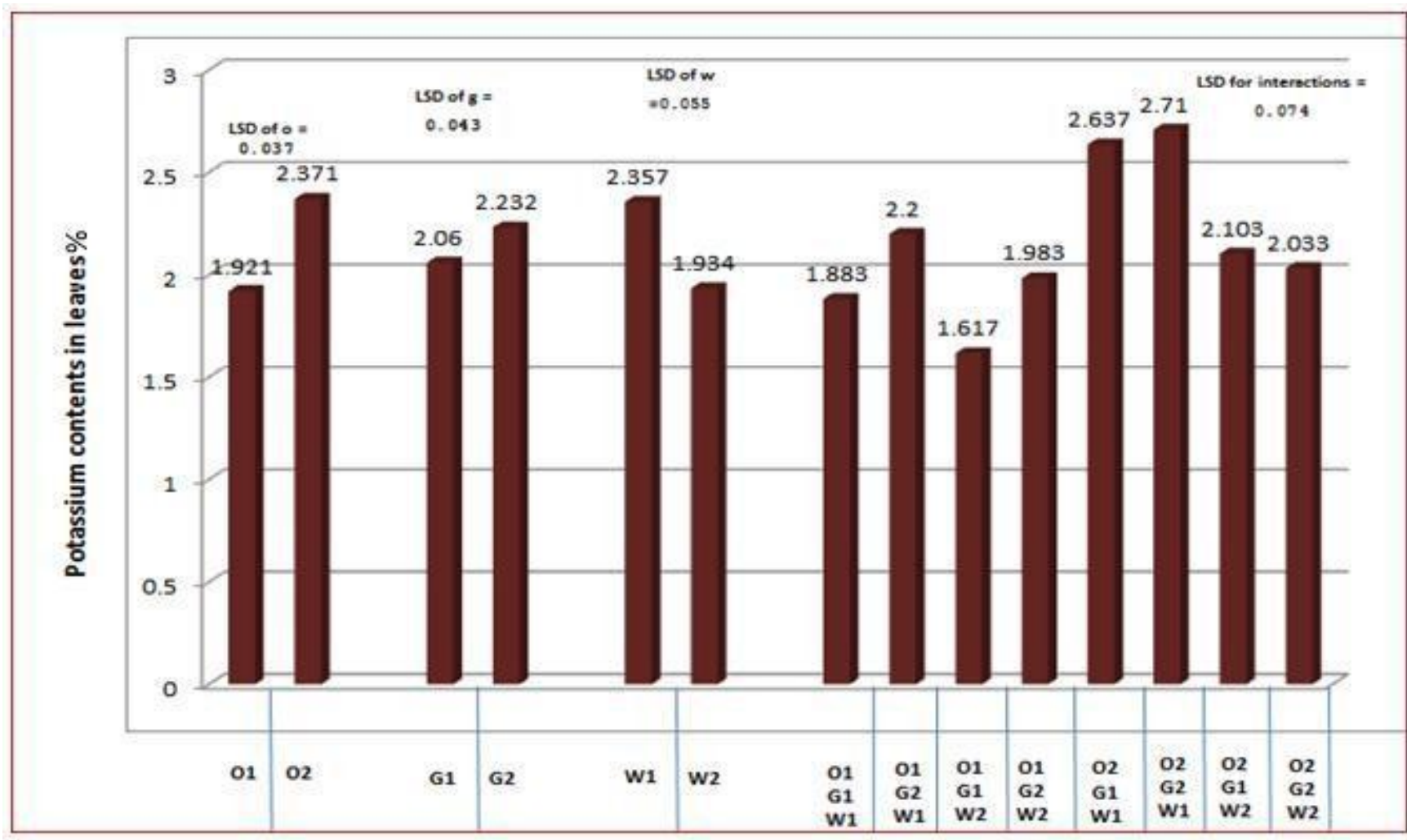

Fig.8: shows the effect of water quality, poultry manure\& gibberellin with interaction betweenthem on the $K$ contentinleaves. Water quality $(W)$ Poultry manure $(O)$ Gibberellin $(g)$ 


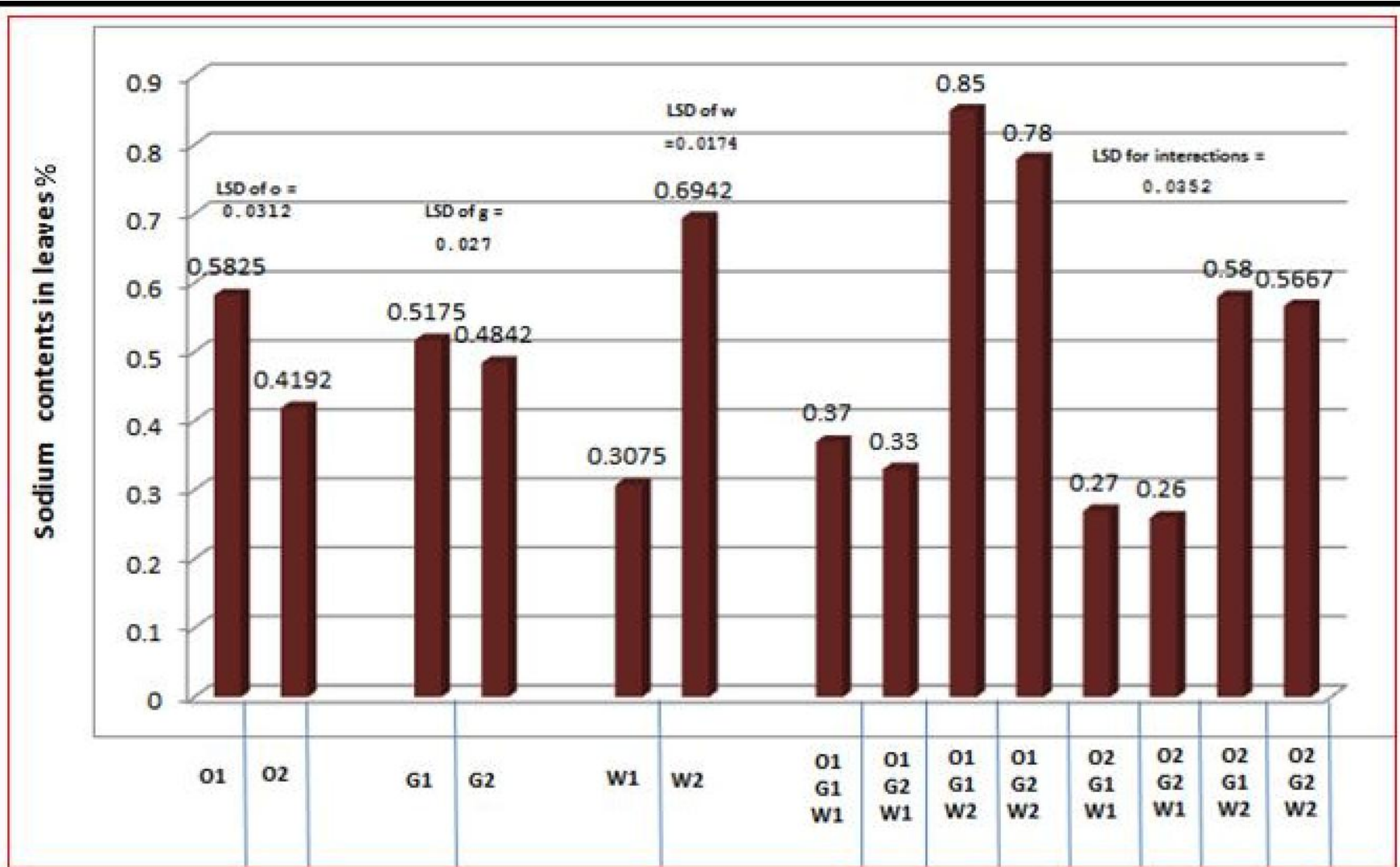

Fig.9: shows the effect of water quality, poultry manure \& gibberellin with interaction betweenthem on the $\mathrm{Na}$ contentinleaves. Water quality (W) Poultry manure (O) Gibberellin(g)

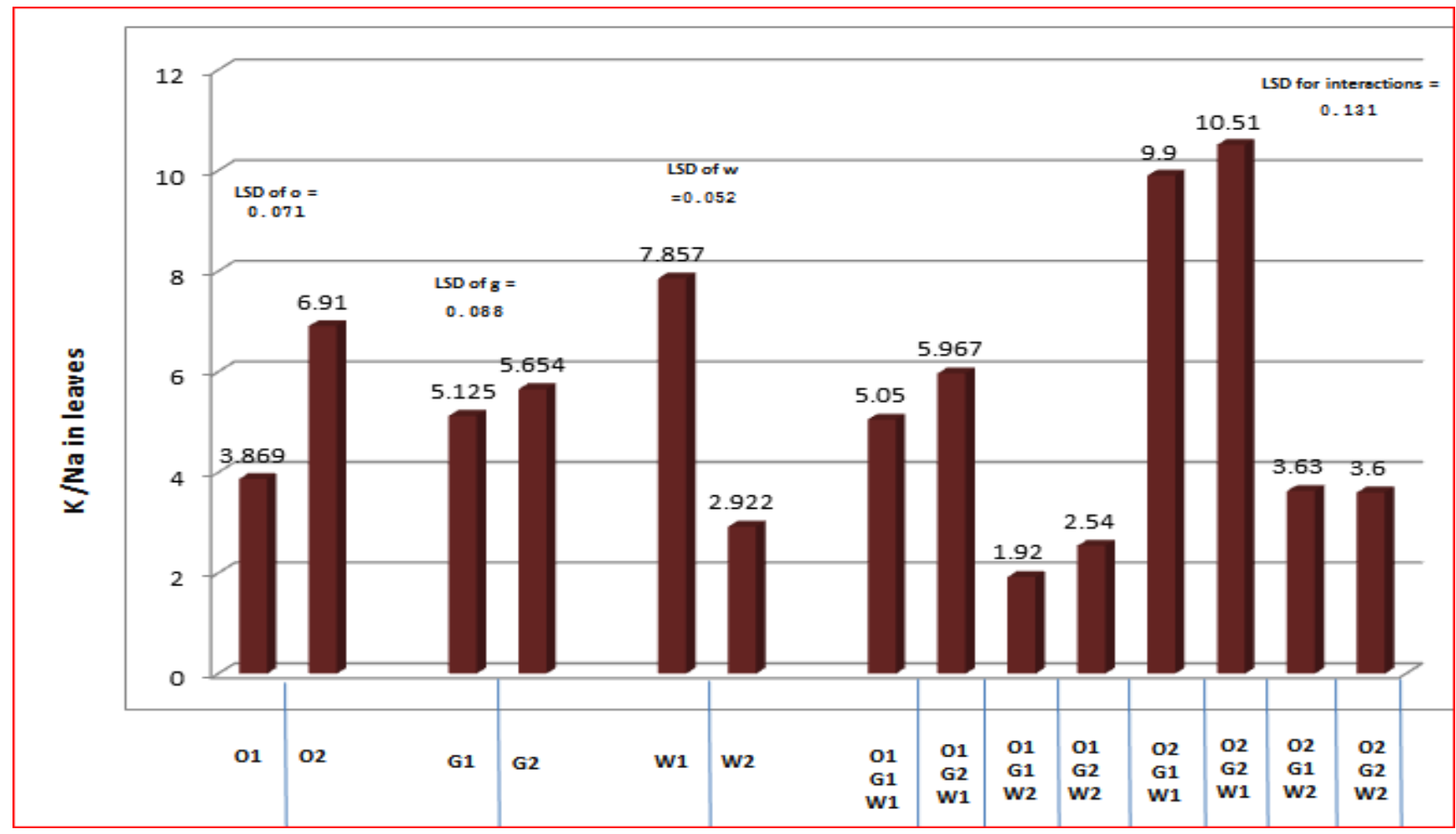

Fig.10: shows the effect of water quality, poultry manure \& gibberellin with interaction between them on the K/Na contentinleaves. Water quality (W) Poultry manure (O) Gibberellin $(g)$ 
3- Proline content in root \& Peroxidase activity inleaves

The figures (11 \& 12) show a significant difference from treatments with proline contents of root and peroxidase activity in leaves, the poultry manure $30 \%$ achieved significant values where boost rate was $(9 \%$ \& $13 \%$ ) sequentially compared with treatment which $10 \%$ poultry manure fertilize, similarly the Gibberellin application by $250 \mathrm{mg}$ /liter produced a significant increments with proline contents of root and peroxidase activity in leaves compared with treatment none Gibberellin treats, and peroxidase activities figures (11 $\&$ 12) shows reductive effect of saline water with dropping rate if ( $78 \%$ \& 49\%) sequentially compared with river water, The tertiary interaction shows a significant affect amongst treatments of proline contents in leaves, the best result was (W2G2O1) \& (W2G2O1) with $(7.81,7.58)$ mmole.$g^{-1}$, sequentially and the lowest result atthetreatment (W1G2O2) with (3.88) mmole. $\mathrm{g}^{-1}$.and the best results of peroxidase activity was (W2G2O1) \& (W2G2O2) with $(102.67,91.33) \mathrm{mg}$ of protein $^{-1}$ sequentially, and the lowest results at the treatment (W1G2O2) with (54.33) mg of protein ${ }^{-1}$ figures $(11,12)$.

The application of poultry manure and gibberellins reduced the negative affect of salinity by saline water, the treatments (W2G1O1) recorded (7.58) mmole. $\mathrm{g}^{-1}$ of proline and (102.67) $\mathrm{mg}$ of protein $^{-1}$ of peroxidase activity compared with $(\mathrm{W} 1 \mathrm{G} 2 \mathrm{O} 2)$ treatment which

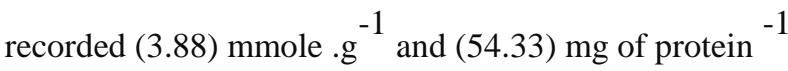
sequentially.

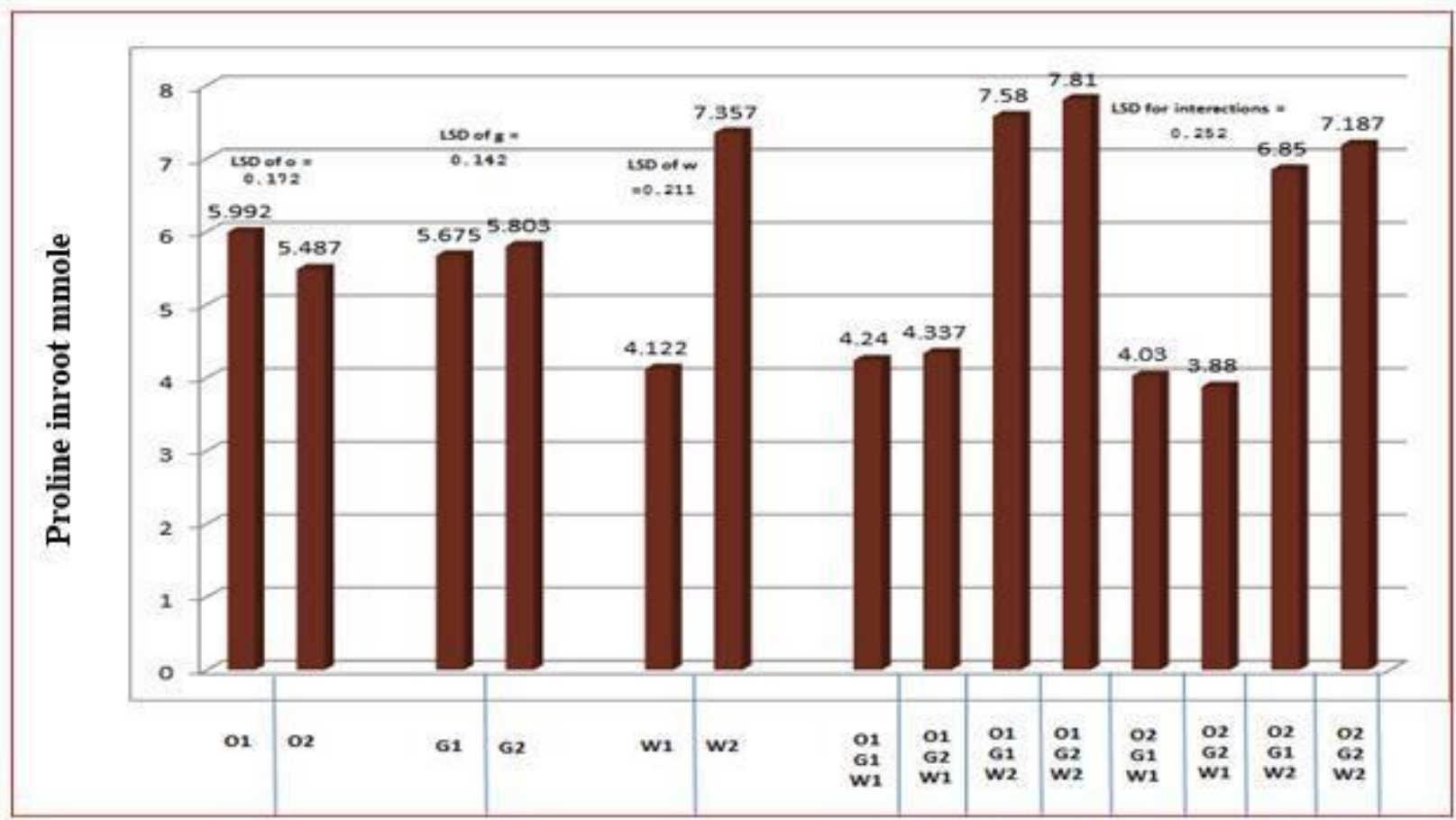

Fig.11: shows the effect of water quality, poultry manure\& gibberellin with interaction between them on Proline content mmole $g^{-1}$ in root. Water quality $(W)$ Poultry manure $(O)$ Gibberellin $(g)$

\section{DISCUSSION}

The figure $(2,3,4,5,6,7,8,10)$ show a significant reduction in dry weight of shoot and root, fruit weight, chlorophyll contents of leaves, Nitrogen, phosphorus, Potassium \& $\mathrm{K} / \mathrm{Na}$, when used saline water compared with river water, similarly ,Jasim, et al (2012)showed that salt stress was negatively affect wet weight, leaves number; leaves surface area and shoot length, The inhibitory effects of salinity on growth of pepper plant the effects of high soil salt availability and are probably due to decreased water absorption and disturbed metabolic processes leading to decreased meristematic activity or cell enlargement (Kaydan and Okut ,2007).Hussein, et al( 2007)reported that there are two ways which salinity could retard growth, by damaging growth cells so that they cannot perform their functions or by limiting their supply of essential metabolites. Salinity stress is known to retard plant growth through its influence on several vital factors of plant metabolism, including osmotic adjustment (Sakr, et al, 2009), nutrient uptake, protein and nucleic acid synthesis, photosynthesis (Zaibunnisa,et al., 2012), organic solute accumulation, enzyme activity, hormonal 
balance and reduced water availability at the cell level all of which result in reduced plant growth and ultimately reduced yield. Furthermore, increased salt content in the irrigation water may cause direct and indirect effects on leaf water relations and stomata closure which influence $\mathrm{CO} 2$ exchange and photosynthetic rate. Increased salt content in irrigation water may be directly toxic to plants, which in turn, lowered carbohydrate accumulation in the plants (Morales,et al.,2008) .

The proline contents in root and peroxidase activity were increased with saline water figure $(11,12)$ respectively, these are one of the role which plant followed to scavenge the reactive oxygen species, the effects of salt stress on plant growth to an increase in reactive oxygen species which play an important role in damaging all classes of biologically important macromolecules including DNA and the generation of $\mathrm{H} 2 \mathrm{O} 2$ and lipid hydro-peroxides which cause membrane changes, To mitigate and repair damage initiated by reactive oxygen, plants have developed a complex antioxidant system. The primary components of this system include some enzymes such as peroxidase (POX), catalase (CAT) super oxidase dismutase (SOD) and proline(Amira and Abdul,2015) The poultry and gibberellins applications alleviated from the negative affect of saline water figures $(2,3,4,5,6$, 7, 8, and 10). Organic fertilizer apart from releasing nutrient elements to the soil has also been shown to improve other soil chemical and physical properties which enhance crop growth and development (Ikeh,et al,2012)In addition, poultry manure has also been reported to increase soil $\mathrm{pH}$, hence the acidic soil of the experimental site which could have caused the unavailability of nutrient element to the crops was checked by the limiting potential of organic manure (Ogbonna, 2008)Moreover, poultry manure contains essential nutrient elements associated with high photosyntheticactivities and thus promoted roots and vegetative growths(John,et al,2004)gibberellin play vital role in regulating developmental processes within plant bodies(Gou ,et al,2010)Gibberellin helps in cell growth of stem, leaves and other aerial parts by causing cell elongation, and increase in intermodal length. A higher concentration of gibberellins increases plant growth (Bora and Sarma, 2007).

Mckenzie and Deyholos, (2011)reported that treatment of GA causes stem elongation, expansion and proliferation and cell wall thickening in bast fiber of linseed, GA3 counteracts with salinity by improving membrane permeability and nutrient levels in leaves which ultimately leads to better growth and also GA3 induced physiochemical changes responsible for induction of salt tolerance (Amal,et al,2014)

\section{CONCLUSIONS}

That possible to mitigation the negative affect of salt stress by some application like exogenous hormones and Decomposed organic matter to solve the disruption of endohormons and lack of available nutrients under salt stress, and elevation of osmotic stress in soil solution in roots area.

The GA \& poultry application improved the growth and it has increased the Pepper tolerance to the abiotic stress which was exerted by saline irrigation water.

\section{KNOWLEDGE}

That possible to mitigate the negative effects of salt stress by some application like exogenous hormones and Decomposed organic matter to solve the disruption of endohormons and lack of available nutrients under salt stress, and Osmotic stress elevation in soil solution in roots area..

We recommended that more researches about salt stress in arid and semi- arid zones to be conducted and the use of other applications from sources of organic matters with studying the phytohormones (Auxins gibberellins , cytokinis , ethylene ,ABA, etc.. in addition to studying the interactions between them on growth and yield to other plants for discovering and increasing the plant tolerance.

\section{REFERENCES}

- Abbaspour H. 2012. Effects of salt stress on lipid peroxidation, antioxidative enzymes and proline accumulation in pistachio plants. Journal of Medicinal Plants Research, 6: 526-529.

- Al-Taey, D. K.A. and A.H. Saadoon.2012. Effect of treatment of kinetin to reduce the salinity damage by drainage water irrigation on the growth, and nitrate accumulation in the leaves of spinach, Spenacia oleracea L. Euphrates Journal of Agriculture Science 4(4):11-24

- Altaey, D.K.A., 2009 Effect of spraying acetyl salicylic acid to reduce the damaging effects of salt water stress on orange plants (Citrus sinensis L.). Journal of Kerbala University; 7 (2) P: $192-$ 202.

- Amal M. E. Abdel-Hamid and H. I. Mohamed\.2014. The effect of the exogenous gibberellic acid on two salt stressed barely cultivars. European Scientific Journal , 10(6):228245

- Amira M. S and A.Q. Abdul Qados.2015. Effects of salicylic acid On growth, yield And chemical contents of pepper (Capsicum Annuum L) plants 
grown under salt stress conditions. International

Journal of Agriculture and Crop Sciences, 8 (2)107-113.

Annu Rev Plant Biol 53:247-273

- Atkinson, N.J. and P.E. Urwin. 2012. The interaction of plant biotic and abiotic stresses: From genes to the field. J. Exp.Bot., 63(10):3523-3543.

- Badar, R., B., Batool., A, Ansari., S, Mustafa., A, Ajmal and S, Perveen.2015. Amelioration of salt affected soils for cowpea growth by application of organic amendments. Journal of Pharmacognosy and Phytochemistry ; 3(6): 8790

- Bates, L.S., R.P, Waldren and I.D. Tears, .1973. Rapid determination of free proline forwater-stress studies. Plant and Cell., 39: 205207.

- Bor ,M., F. Özdemir., I .Türkan .2003. The effect of salt stress on lipid peroxidation and antioxidants in leaves of sugar beet Beta vulgaris L. and wild beet Beta maritima L. Plant Science 164(1): 77-84.

- Bora, R.K and C.M. Sarma .2006. Effect of gibberellic acid and cycocel on growth, yield and protein content of pea. Asian Journal of Plant Sciences 5: 324-330.

- Colebrook,E.H., S.G. Thomas, A.L. Phillips and P. Hedden,.2014. The role of gibberellin signaling in plant responses to abiotic stress, J. Exp. Biol. 217 : 67-75.

- Eletr W.M.T., F.M. Ghazal., A.A. Mahmoud. G.H. Yossef. 2013. Responses of wheat - rice cropping system to cyanobacteria inoculation and different soil conditioners sources under saline soil. Nature and Ncience; 11(10):118129.

- El-Sidding, K., and P. Ludders. 1994. Interactive effects of nitrogen nutrition and salinity on reproductive growth of apple trees. Gartenbauwiss 59: 127-131.

- Faiza Sharif, U., and K.Amin. 2009. Alleviation of salinity tolerance by fertilization in four thorn forest species for the reclamation of salt. Pak. J. Bot. 41(6): 2901-2915.

- Gomez, I., J. Pedreno., R. Morel, M. R. Iborra, G. Palacios, and J. Mataix. 1996. Salinity and nitrogen fertilization affecting the macronutrient content and yield of sweet pepper plants.
Journal of Plant Nutrition 19: 353-359.

ISSN: 2456-1878

- Gou J., S.H. Strauss, C.J. Tsai., K.Fang. Y. Chen., X. Jiang and V.B. Busov .2010. Gibberellins regulate lateral root formation in Populus through interactions with auxin and other hormones. The Plant Cell 22: 623- 639.

- Hussein M.M., K. Balbaa And M.S. Gaballah .2007. Salicylic acid and salinity effects on growth of maize plants. Research Journal of Agriculture and Biological Sciences,3(4): 321328

- Ikeh, A. O., N. U. Ndaeyo., I. G. Uduak., G. A. Iwo., L. A. Ugbe., E. I.Udoh1 and G. S. Effiong .2012. Growth and yield response of pepper (Capsicum frutescens L.) to varied poultry manure rates in Uyo, Southeastern Nigeria. Journal of Agricultural and Biological Science, 9 (7): 735-742.

- Jackson, M.L. 1958. Soil chemical analysis . Prentice Hall. Englewood Cliffs. N.J.

- Jimenez-Garcia, S.N., M.A. Vazquez-Cruz ., L .Garcia-Mier.,R.G.uevara- onzalez.,I.TorresPacheco, R.V. Ocampo-Velazquez., A. CruzHernandez., A.A. Feregrino-Perez .2014. Changes in the quantity of phenolic compounds in peppers (Capsicum annuum L.) sprinkled with elicitors under cold stress. J. Chem. Biol. Phys. Sci .4(5):11-17

- John, L. W., D. B. Jamer., L. T. Samuel and L.W. Warner.2004 . Soil fertility and Fertilizers : An introduction to nutrient management . Person Education, Delhi. 106 - 153.

- Kaydan D, and M.Y. Okut .2007. Effects of salicylic acid on the growth and some physiological characters in salt stressed wheat (Triticum aestivum L.). Tarim Bİlimleri Dergisi, 13(2): 114-119.

- Kijne, J.W. 2003. Unlocking the water potential of agriculture. F.A.O corporate document repository, Rome, Italy.

- Lee, S.K.D. 2006. Hot pepper response to interactive effects of salinity and boron. Plant Soil Environment. 52: 227-233.

- Maggio A., Barbieri G., G. De Raimondi and S. Pascale .2010. Contrasting effects of GA3 treatments on tomato plants exposed to increasing salinity. J Plant Growth Regul. 29:63 -72.

- Marin J.A., P. Andreu., A. Carrasco and A. Arbeloa,.2010. Determination of proline

Page | 1861 
concentration, an abiotic stress marker, in root exudates of excised root cultures of fruit tree rootstocks under salt stress. Revue Des Régions Arides - Numéro Spécial .24 (1): 722-727.

- Morales G, K.A. Stewart., and P.Seguin. 2008. Effects of saline water on growth and physiology of bell pepper seedlings. International Journal of Vegetable Science , 14: $121-138$

- Munteanu,V., V. Gordeev., R. Martea and M. Duca. 2014. Effect of gibberellin cross talk with other phytohormones on cellular growth and mitosis to endoreduplication transition. Int. J. Adv. Res. Biol. Sci. 1 (6) : 136-153.

- Ogbonna, P. E.2008. Effect of combined application of organic and inorganic fertilizers on fruit yield of eggplant (Solanum melongena). Proceeding. 42nd Ann.Conf. of Agric. Soc. of Nigeria. Abakaliki, Nigeria19 - 23 October p. $236-250$.

- Page, A.L., R. H. Miller and D. R. Keeney 1982. Methods of soil and analysis Part 2, 2nd ed, Agron. 9, Madison, W.

- Sakr, M.T., M.E. El-Emery., R.A. Fouda and M.A. Mowafy .2009. Role of some antioxidants in alleviating soil salinity stress. J. Agric. Sci. Mansoura. univ. 32:9751-9763.

- Sana, T., M.A, Chaudhry, A, Muhammad and A. Rashid. 2016. Assessment of salinity tolerance in Bell Pepper (Capsicum annum L.) genotype on the basis of germination emergence attributes. Pak. J. Bot., 48(5): 1783-1791,

- Shabir H. W., V. Kumar., V. Shriram and S. K. Sah .2016. Phytohormones and their metabolic engineering for abiotic stress tolerance in crop plants. Therop Journal 4: 162-176.

- Shahbaz, M. and M. Ashraf. 2013. Improving salinity tolerance in cereals. Crit. Rev. Plant Sci, 32: 237 - 249

- Skirycz,A., H. Claeys, S. De Bodt, A. Oikawa, S. Shinoda, M.Andriankaja, K. Maleux, N.B. Eloy, F. Coppens, S.D. Yoo, K.Claeys,H. A. Skirycz, K. Maleux and D. Inze,.2012. DELLA signaling mediates stress-induced cell differentiation in Arabidopsis leaves through modulation of anaphase promoting complex cyclosome activity, Plant Physiol. 159: 739 747.
- Tayyab, M., M. Qasim, N. Ahmad and R. Ahmad. 2016. Salt stress responses of pigeon pea (Cajanus cajan) on growth, yield and some biochemical attributes., Pak. J. Bot., 48(4): 13531360 .

- Trinder P, .1966. Determination of glucose in blood using glucose oxidase with an alternative oxygen acceptor, Ann. Clin. Biochem. 22(2):158161.

- Wiessmann, H. and K. Nehring .1960. Agriculture Chemical analysis Gsm methods for fertility and animal feed, boden und milek. dritte voellig. neubeasrbeitete auflage verlag paul parey . Hamburg und Berlin

- Wong V.N.L., R.C. Dalal and R.S.B. Greene. 2009. Carbon dynamics of sodic and saline soil following gypsum and organic material additions: laboratory incubation. Appl. Soil. Ecol. 41:29-40.

- Younes, K.A., S.S.Raouf., S. Mohammad and B. Morteza .2016. Effect of zinc and bio fertilizers on antioxidant enzymes activity,chlorophyll content, soluble sugars and proline in Triticale under salinity condition. Not. Bot. Horti. Agrobo.44(1):116-124.

- Zaibunnisa A., M.A. Khan., T.J. Flowers., R. Ahmad and K.A. Malik. 2002. Causes of sterility in rice under salinity stress. In: Ahmad, R. (ed.) Prospects for saline-agriculture. Kluwer. The Netherlands.

- Zhu, J.K. 2002. Salt and drought stress signal transduction in plants . 